\title{
Interesse público ou public interest? Holismo e individualismo em ações judiciais coletivas no Brasil e nos Estados Unidos
}

\section{Márcio de Paula Filgueiras}

\section{(2) OpenEdition}

Journals

Edição electrónica

URL: http://journals.openedition.org/aa/1620

DOI: 10.4000/aa.1620

ISSN: 2357-738X

Editora

Programa de Pós-Graduação em Antropologia Social (UnB)

\section{Edição impressa}

Data de publição: 1 julho 2016

Paginação: 57-79

ISSN: 0102-4302

\section{Refêrencia eletrónica}

Márcio de Paula Filgueiras, «Interesse público ou public interest? Holismo e individualismo em ações judiciais coletivas no Brasil e nos Estados Unidos», Anuário Antropológico [Online], v.41 n. 1 | 2016 , posto online no dia 07 junho 2018, consultado o 28 abril 2021. URL: http://journals.openedition.org/ aa/1620 ; DOI: https://doi.org/10.4000/aa.1620

\section{(c) $($ ) $(3)$}

Anuário Antropológico is licensed under a Creative Commons Atribuição-Uso Não-Comercial-Proibição de realização de Obras Derivadas 4.0 International. 


\title{
Interesse público ou public interest? Holismo e individualismo em açóes judiciais coletivas no Brasil e nos Estados Unidos
}

\author{
Márcio De Paula Filgueiras
}

IFES

O direito é um dos temas mais tradicionais da antropologia. Essa foi a resposta que me acostumei a dar às pessoas com quem interagi durante o doutorado e que se surpreendiam com a ideia de um antropólogo que estudava o direito. Afinal, antropólogo ou advogado? Nas oportunidades em que o diálogo se estendia, explicava que minha formaçáo era em antropologia e que eu estudava o direito do Brasil e dos Estados Unidos com uma curiosidade intelectual treinada, mas que os não antropólogos ainda esperam ver realizada somente a respeito de um outro exótico e distante, de preferência "não Ocidental".

Isso ficou claro sobretudo em minha chegada aos Estados Unidos, ${ }^{1}$ quando a explicitação dessas questóes aos meus primeiros interlocutores nativos, não acadêmicos, eventualmente alcançava um momento de perplexidade, ainda que sob um clima descontraído e jocoso, com a fatídica pergunta: "então você veio aqui nos estudar?” ou "entáo somos os índios da sua pesquisa?”. Dados os aspectos de poder que atravessam historicamente as relaçôes entre Estados Unidos e Brasil, percebi que algumas pessoas, principalmente as que não tinham treinamento em ciências sociais, ficavam desconcertadas pela ideia de que sua sociedade — ou seja, eles próprios, norte-americanos - pudesse ser objeto de pesquisa antropológica, ainda que isso fosse amenizado pela polidez descontraída da interação.

Mas, de fato, um olhar sobre a trajetória da disciplina permite perceber que o direito está presente desde as primeiras questóes formuladas pelos antropólogos. ${ }^{2}$ Assim, tendo sido formado na tradição acadêmica da antropologia, sempre me surpreendi com o estranhamento de alguns de meus interlocutores diante da ideia de o direito ser objeto de reflexão antropológica.

Neste texto, o interesse antropológico pelo direito partirá de um cuidado em tratar os termos jurídicos como categorias sociais. As categorias sociais são uma preocupação fundamental da antropologia desde, pelo menos, as contribuiçóes de autores franceses como Marcel Mauss e Émile Durkheim. Esses autores demonstraram que o pensamento humano acontece a partir de princípios que são transmitidos socialmente, por meio de processos em que um indivíduo torna-se membro de uma coletividade e aprende com esta as formas de ver o mundo que 
correspondem à sua cultura. Nesse sentido, combateram tanto a perspectiva empirista, segundo a qual o pensamento humano seria passivo diante da realidade, limitando-se a reproduzi-la abstratamente, quanto a perspectiva dos aprioristas, segundo a qual o pensamento humano seria produto de categorias universais e inatas, que expressariam uma razão a-histórica.

Tomando os termos jurídicos como categorias sociais, podemos compreender seu papel de "princípios de juízos e raciocínio" (Mauss \& Henri, 2014), ou seja, palavras carregadas de significados que constituem a "ossatura da inteligência" (Durkheim, 1973), capazes de ordenar o pensamento, emprestando-lhe significado e referência semântica. É com esse espírito e atitude mental que tratarei as categorias "interesse público" e public interest neste artigo. Trata-se de um exercício comparativo, com ênfase no contraste entre os significados dessas categorias, tomando em consideração as culturas políticas e jurídicas das quais fazem parte. Essa comparação relativizadora constitui um desafio especial porque ambas as sociedades em foco estão situadas no continente americano, são pós-coloniais, capitalistas, e se sentem herdeiras de sistemas políticos e jurídicos surgidos na Europa Ocidental.

Louis Dumont (1994) abordou esse tipo de dificuldade em seu estudo sobre ideologias nacionais. Segundo o autor, só podemos compreender os significados das ideologias nacionais dominantes em diferentes sociedades quando as colocamos em contraste umas com as outras, ou seja, de forma relacional. Esse é o caso das ideologias nacionais de França e Alemanha, estudadas pelo autor. Apesar de aparentemente semelhantes, essas sociedades podem ser contrastadas do ponto de vista de suas ideologias nacionais, quando observamos a forma como se estruturam as relaçóes entre dois princípios organizadores do pensamento humano: o individualismo e o holismo.

Assim, as questóes a que busco responder dizem respeito a um tema amplamente estabelecido na antropologia, a saber, o das diferenças entre sociedades organizadas segundo princípios holistas, em que o valor está no todo social, e aquelas baseadas no indivíduo como um valor moral (Dumont, 1994; 2000). Neste artigo, vou mostrar como essa problemática constitutiva do campo antropológico pode lançar luz sobre a compreensão dos significados subjacentes às concepçôes predominantes de interesse público no Brasil e nos Estados Unidos e como estas se expressam na estrutura processual das açóes judiciais coletivas nos dois países.

Como veremos, no Brasil, muitas ações legais são iniciadas, sobretudo pelo Ministério Público, tendo como razão a proteção do interesse público "para toda a sociedade e as futuras geraçóes”, como escutei de promotores em algumas 
ocasiōes. Os “legitimados” para ajuizar açôes em defesa do interesse público são definidos por lei. Grande parte desses legitimados são instituiçôes públicas, como o Ministério Público. ${ }^{3}$ No caso das organizaçóes não governamentais, basta que entre seus objetivos, descritos em estatuto, esteja, por exemplo, a proteção do meio ambiente. Isso lhes permite atuar como "legitimados" para a defesa judicial do meio ambiente em nome da sociedade brasileira "como um todo". Não precisam provar que representam grupos ou segmentos sociais específicos com algum interesse concreto no caso.

Nos Estados Unidos, por outro lado, para ser aceita pela Corte, uma ação legal para a proteção de interesse público deve apontar grupos legalmente identificáveis que estejam sofrendo um dano e possuam, portanto, a suficcient stake in the matter, ${ }^{4}$ não apontar para um interesse público genérico, como o "de toda a sociedade" ou das "futuras e presentes geraçóes". Açóes que tenham como motivação a proteção de meio ambiente "para todos" geralmente são recusadas pelas Cortes por se referirem a um interesse público "indiferenciado".

Assim, no Brasil, os grupos e as instituições que ajuízam açóes para a proteção do interesse público, sobretudo em casos que envolvam o meio ambiente, recorrentemente procuram mostrar que os interesses que reivindicam são os interesses de "toda a sociedade". Já nos Estados Unidos, para ser bemsucedido, o grupo que ajuíza uma ação desse tipo deve mostrar que seus interesses não se confundem com os interesses do resto da sociedade, e que sofreu um dano específico.

Há de se notar também que nos Estados Unidos não é um ente do Estado, como o Ministério Público brasileiro, mas escritórios privados de advocacia, atores do mercado, que agem legalmente nesses casos. Existe, portanto, uma solidariedade ideológica entre o papel de escritórios privados de advocacia, que apontam para o entendimento do interesse público como algo a ser promovido por entes que atuam no mercado, e uma concepção atomista de bem comum, recorrentemente reforçada pelas decisóes judiciais, que se refere a grupos específicos, legalmente identificáveis, e não a interesses distantes e impessoais como "a sociedade norte-americana”.

Esse modelo reproduz seu capital simbólico ao apontar para princípios jurídicos e políticos liberais que possuem grande eficácia discursiva nos Estados Unidos: a concepção do interesse público como resultado das açóes de atores segundo uma lógica de mercado (e não como resultado da intervenção de um "Estado pacificador", como afirmam os juristas no Brasil); e a crença de que as Cortes só devem decidir a respeito de casos e controvérsias, ou seja, sobre direitos específicos, relacionados a grupos concretos - diferente do Brasil, porque aqui 
o entendimento do meio ambiente como um direito difuso permite considerar entidades imprecisas, como "a sociedade brasileira e suas futuras geraçôes", como detentores de direitos, que devem ser tutelados pelo Estado. ${ }^{6}$

A concepção pacificadora do Estado, como entendida no campo jurídico brasileiro, já foi observada por Kant de Lima (2008) e expressa uma crença amplamente estabelecida em nossa sociedade de que o espaço público é composto de interesses "egoísticos" inconciliáveis, que só poderiam ser pacificados pela ação do Estado. São, portanto, ideias bem específicas que encontram solidariedade: a crença em um Ministério Público que representaria o Estado pacificador distante e impessoal (e, portanto, imparcial) e a definição do interesse público como algo abrangente e indefinido como "a sociedade brasileira".

Meu argumento é que essas diferenças indicam princípios contrastantes na definição de interesse público: uma perspectiva mais holista no direito brasileiro e outra mais individualista ou atomista no direito dos Estados Unidos. A seguir, vou apresentar aspectos de um conflito que acompanhei em Vila Velha (ES) e que teve repercussões judiciais e extrajudiciais. Esse conflito envolve uma ação direta de inconstitucionalidade, que inclui discussóes sobre parâmetros urbanísticos e ambientais e permite identificar alguns paradoxos da definição de interesse público no Brasil. Em seguida, apresentarei os Estados Unidos como referência comparativa, procedimento heurístico através do qual as particularidades de cada sociedade ficarão explícitas.

\section{O interesse público nas açóes judiciais coletivas no Brasil}

Conversas com participantes de movimentos sociais em Vila Velha-ES apontaram uma congruência histórica entre os interesses de ocupantes do Executivo e Legislativo municipais e os interesses dos representantes da indústria da construçáo civil que atua localmente. Essa seria a principal explicação para o acelerado processo de verticalização na orla do município nos últimos trinta anos. Pode-se considerar que essa é uma das principais bandeiras críticas do ambientalismo local nos últimos anos, junto da preservação dos rios e canais naturais, dos parques e das matas nativas.

Segundo a sabedoria convencional de militantes e moradores da região, a ocupação excessiva do solo, que causa sua impermeabilidade, associa-se ao desmatamento, que assoreia os rios e canais, que acabam transbordando durante as chuvas. Como consequência, bairros inteiros são inundados e o trânsito torna-se impossível, além de perigoso. Isso tudo vem à tona de maneira cíclica, quando das chuvas de fim de ano. Corresponde a esses eventos naturais o aumento, também cíclico, da discussão do assunto na mídia, que se ameniza no resto do ano. 
As recentes discussões sobre o Plano Diretor Municipal de Vila Velha (PDM) ${ }^{7}$ podem ser vistas como parte desse enredo mais amplo, que envolve urbanização do município, alagamentos, cooptação do poder público e etc. Acompanhei este conflito em diferentes contextos, como audiências públicas, protestos, seminários, reuniōes, rede social e, sobretudo, junto ao Fórum Popular em Defesa de Vila Velha (FPDVV), organização da sociedade civil com cujos membros interagi diretamente e com frequência em reuniôes, pelo menos duas vezes por mês, ao longo do ano de 2012.

O Ministério Público Estadual (MP/ES) iniciou duas ações diretas de inconstitucionalidade (Adin) entre 2007 e 2011, tendo como objeto dois Planos Diretores Municipais. A primeira Adin referia-se à Lei 4.575/2007. ${ }^{8}$ Trata-se de uma lei elaborada pelo Legislativo municipal a partir do Projeto de Lei 034, que foi construído com ampla participação popular, segundo me disseram membros de entidades do FPDVV. No entanto, quando foi transformado na Lei 4.575/2007, o projeto teria sofrido grandes alteraçóes pela Câmara Municipal. Mesmo com o veto do então prefeito Max Filho, a Câmara promulgou a lei, que foi razão para a primeira Adin pelo MP/ES. Quatro anos depois, essa primeira Adin ainda não havia sido julgada pelo Tribunal de Justiça, quando a Prefeitura, à época sob mandato de Neucimar Fraga, aprovou a Lei 5.155/2011, também sem participação popular. Essa lei foi objeto de nova Adin pelo MP/ES. A primeira Adin resultou na declaração de inconstitucionalidade de treze artigos da Lei 4.575/2007. Já a Lei 5.155/2011 foi considerada inconstitucional na íntegra pelo Tribunal de Justiça do ES.

De maneira geral, essas ações judiciais questionavam a forma como o PDM havia sido alterado pela Câmara Municipal, sem consulta à populaçáo, e o conteúdo das emendas legais, que alteravam parâmetros urbanísticos como coeficiente de ocupação do solo e definição da altura das edificaçôes, além de transformar áreas de interesse ambiental em áreas de interesse industrial, econômico e turístico.

A partir da declaraçáo de inconstitucionalidade dos treze artigos da Lei 4.575/2007 e da íntegra da Lei 5.155/2011, produziu-se o que alguns interlocutores da pesquisa, como o presidente do Sindicato das Indústrias da Construção Civil (Sinduscon), chamaram de "vácuo legal", cuja remediação se deu por meio de negociaçóes que aconteceram no Conselho de Desenvolvimento Urbano (Comdur), envolvendo atores tais como CCVV (Conselho Comunitário de Vila Velha), Conselho de Arquitetura, Sinduscon e Secretaria Municipal de Planejamento Urbano. O Comdur é previsto pelo Estatuto das Cidades. Algumas reuniōes também aconteceram na sede do MP/ES. 
Quando o texto produto dessas discussóes estava pronto para ser encaminhado para a Câmara Municipal, o MP/ES convocou uma reuniáo em sua sede, por solicitaçáo do FPDVV, que náo participava do Comdur e vinha questionando a representatividade das entidades da sociedade civil que participavam do conselho, acusando-as de serem cooptadas pelo Executivo municipal. ${ }^{?}$

Como pude perceber desde o início, o FPDVV reunia pessoas e entidades orientadas por perspectivas sensivelmente diferentes a respeito do meio ambiente, da melhor forma de protegê-lo, dos impactos das mudanças ambientais nas camadas da população e assim por diante. Ainda que o objetivo não seja traçar um panorama aprofundado sobre o campo ambiental local (Lobino, 2008), ficou claro para mim em ocasióes como reuniôes ou demonstraçóes públicas que a linguagem utilizada por representantes das entidades, movimentos populares e vereadores era bastante variável, desde uma linguagem no sentido de "conscientizar" empresários e agentes públicos sobre a importância do meio ambiente (Movimento Vida Nova Vila Velha - Movive, por exemplo) até outras que faziam referência ao papel do "capitalismo" e da "luta de classes" nas questôes ambientais (Movimento Jacarenema; Federação das Associaçôes e Movimentos Populares do Espírito Santo - Famopes).

$\mathrm{Na}$ reunião que descreverei a seguir, realizada na sede do MP/ES, os promotores apresentaram-se como "conciliadores" entre os interesses dos grupos presentes, incluindo a Câmara Municipal e a Prefeitura, representada pelo procurador do município e a Secretaria de Desenvolvimento Urbano. Outras partes interessadas presentes eram o Sinduscon e o FPDVV. Vejamos a fala de uma promotora em entrevista:

[...] recentemente o Ministério Público atuou na conciliação entre sociedade, representantes do Executivo, do Legislativo e sociedade civil para o projeto de lei que foi encaminhado e regulamentado [...].

[...] Foi o MP que fez esse trabalho, né, conciliando os interesses, então nós queremos que nosso estado se desenvolva cada vez mais, mas que de fato se dê com base no princípio do desenvolvimento sustentável, que seja preservado esse estado em que a gente vive para as presentes e futuras geraçôes $[. ..] .^{10}$

Tendo acompanhado os desdobramentos desse conflito a respeito do PDM de Vila Velha, identifiquei como o FPDVV encontrou aliados políticos nos promotores do Ministério Público da cidade. Os promotores, por outro lado, têm no FPDVV a base social que legitima suas açóes. Relevante para entender meu argumento é que, em evento no Centro Universitário de Vila Velha, a promotora Maria afirmou que foi "a sociedade" que procurou o Ministério Público sobre o PDM: "o Ministério Público instaurou um inquérito civil depois que a sociedade 
o procurou". Ela não se referiu especificamente ao FPDVV ou algum outro grupo. Essa linguagem holística é comum nas falas dos promotores e busca estabelecer legitimidade às suas açóes, protegendo-as da acusação de serem capturadas pelos interesses de grupos específicos.

Assim, no sentido utilizado pela promotora, interesse público refere-se ao interesse da totalidade da sociedade. Ora, como minha pesquisa revelou, não foi "a sociedade", mas um grupo específico de cidadáos, ligados ao FPDVV, que procurou o Ministério Público. Quando esse interesse, de um grupo específico, é referido pela promotora como o interesse "da sociedade", aquilo que era uma parte passa a representar o todo. Parece-me que a legitimidade do Ministério Público para ajuizar causas em nome do interesse público depende, sobretudo nas situações que concernem ao meio ambiente, de que esse interesse público seja apresentado como o interesse da totalidade da sociedade.

Essa não foi uma fala isolada. Encontrei, nas açóes ajuizadas pelo MP/ES referentes a esse caso, tal concepção holista de interesse público, em noçóes abrangentes e indeterminadas como "as presente geraçôes": "urge, pois, que se estabeleça o direito fundamental da presente geração a viver numa cidade que prima pelo desenvolvimento sustentável". ${ }^{11}$

As falas dos promotores oscilam entre esta autoimagem de "representantes da sociedade" e a autorreferência, também recorrente, de que são "conciliadores" entre os grupos. Em certo sentido, se apresentam como capazes de promover a síntese de interesses que formariam um interesse público abrangente. Os promotores que acompanhei tem usado o termo "orquestração", além de "conciliação", para designar seu papel nesse conflito.

Fica obscurecido assim o fato de que os próprios promotores possuem interesses que estáo mais afinados com os de um determinado grupo do que de outro. A observação deixou clara certa polarização entre, de um lado, o Ministério Público e o FPDVV e, de outro, a Câmara Municipal, a Prefeitura e o Sinduscon. Assim, a fala dos promotores de que representam os interesses "da sociedade" contrasta com a proximidade, observada empiricamente, que possuem com determinados grupos. Afinal, os promotores são parte judicial nos processos sobre o PDM, ao mesmo tempo em que reivindicam o papel de conciliadores imparciais nos desdobramentos extrajudiciais do mesmo conflito.

\section{Uma reunião na sede do Ministério Público Estadual}

Nesta seção, descreverei uma reuniáo na sede do MP/ES. Trata-se de um dos momentos em que os promotores atuaram como "conciliadores" extrajudiciais. Como mostrarei, a ambiguidade à qual me referi acima resultou em uma conduta 
por parte dos promotores, que pareceu pouco previsível e transparente aos olhos dos atores envolvidos, independente de suas posições relativas no conflito.

A reuniáo foi iniciada por volta das $9 \mathrm{~h} 15$. $\mathrm{Na}$ mesa central, estavam três promotores estaduais ${ }^{12}$ e duas assessoras. A promotora Carla, coordenadora estadual do CAOA, ${ }^{13}$ abriu a reuniáo fazendo um discurso sobre como o Ministério Público percebeu que a implantação de políticas públicas precisa ser "consertada" para "evitar a conflituosidade". Disse que os presentes deviam deixar de lado os interesses pessoais, porque o "espírito de briga" devia ter sido superado depois da decisão do Tribunal de Justiça pela inconstitucionalidade dos treze artigos do PDM (Lei 4.575/2007). Disse ainda que a reuniáo devia buscar um equilíbrio entre as perspectivas social, econômica e ambiental e que as negociaçóes deveriam se dar em termos técnicos; era necessário não ser intransigente, mas "se colocar no lugar do outro".

Outra promotora, Maria, apresentou de maneira enfática os marcos sobre os quais aquela reunião deveria se pautar: compreender a cidade como um grande condomínio; entender o PDM como um estatuto de "convivência pacífica"; observar a cidade como espaço da lei e da democracia representativa; considerar que a política urbana deve caminhar dentro da ordem econômica e da ordem ambiental e social e que era preciso conciliar a "agenda marrom", da indústria civil, com a "agenda verde", do meio ambiente. A promotora fez referência também ao artigo $5^{\circ}$ da Lei 4.575/2007, que fala da função social da propriedade.

Chamou-me atenção o fato de que a promotora Maria conduzia a reunião e tinha certa proeminência em relação aos outros dois promotores, além de ser mais velha que eles. Ela usava em suas intervençôes, um tom enfático, balançando sua caneta como se fosse continuação de seu dedo indicador, gesto que é recorrentemente usado por pessoas em posição de autoridade. Ela procedeu dessa forma em diversas falas, inclusive chamando a atenção de um dos presentes à reuniáo para prestar atenção, já que a pessoa havia virado para trás e feito algum comentário. Em outra ocasião, em um evento no Centro Universitário Vila Velha, a promotora pediu licença à mesa para, diferente dos outros palestrantes, falar de pé; ela explicou que isso era característica de promotor de Justiça, "gostar de falar de pé".

Após a fala da promotora Maria, a secretária de Desenvolvimento Urbano da Prefeitura de Vila Velha foi incumbida de apresentar o Projeto de Lei (PL) que seria votado ainda naquela tarde pela Câmara de vereadores, substituindo assim os treze artigos inconstitucionais da Lei 4.575/2007. A promotora sugeriu que o PL fosse apresentado, que as pessoas fizessem observaçóes aos artigos que precisassem ser esclarecidos e que, em seguida, estes fossem retomados individualmente, como forma de otimizar o uso do tempo. 
Logo no início da apresentação, foi solicitado que o texto do PL fosse projetado na parede, para que todos pudessem acompanhar sua leitura. O representante da indústria da construção civil ofereceu seu dispositivo pen drive e computador para a projeção. Em seguida, instaurou-se uma pequena confusão sobre qual seria o texto que estava sendo apresentado, já que os membros do FPDVV disseram que não era aquela versão que tinham recebido. Os três promotores à mesa sugeriram que, mesmo assim, a apresentação deveria continuar, já que, como destacou a promotora Maria, "não podemos perder este momento".

Quando começaram a surgir discordâncias sobre o texto, a promotora Carla destacou que aquele náo era o espaço apropriado para mudar o texto apresentado pela Prefeitura, já que aquela não era, formalmente, uma audiência pública. Teoricamente, o texto apresentado como PL deveria ser aquele que restou, depois da decisão do Tribunal de Justiça, acrescido das discussóes realizadas no Comdur, instância prevista pelo Estatuto das Cidades que reúne uma variedade de atores, como representantes da sociedade civil, da indústria da construção civil, do conselho de arquitetura e do poder público. No entanto, como veremos, a reuniáo no Ministério Público acabou servindo para alteraçôes na lei, o que foi apontado como ilegítimo pelo presidente do Sinduscon.

Chegando ao final da exposição do $\mathrm{PL}$, depois de não haver grandes controvérsias e após aparente insucesso do FPDVV em indicar inconsistências no texto, surgiu um impasse relativo a alguns quadros aos quais remetia o artigo 137 da Lei 4.574/2007, que tratavam de parâmetros urbanísticos, como os índices de ocupação do solo, ${ }^{14}$ e que haviam sido considerados inconstitucionais pelo Tribunal de Justiça. A promotora Carla, pelo menos por três vezes, coibira tentativas do FPDVV de sugerir mudanças no texto, porque, segundo ela, aquele não era o fórum apropriado para isso. Ela enfatizou que aquele não seria o espaço para "acordinhos". ${ }^{15}$ Segundo ela, fazê-lo seria táo inconstitucional quanto o PDM derrubado pelo Tribunal de Justiça. Para tanto, ela fez referência ao que chamou de "princípio da legalidade", condição fundamental, segundo ela, para a democracia. Como registrado na ata da reunião,

dada a palavra ao representante da sociedade civil, foi proposto um acordo de manter determinada área da Praia da Costa como ZOP $2^{16}$ para minimizar o problema da mobilidade. Dada a palavra a Dra. Carla, foi dito a impossibilidade de acordo, pois não se trata de fórum legítimo para tanto, pois não pode ser pactuado nada que será questionado a constitucionalidade adiante. O norte que pauta esta reunião é o princípio da legalidade e a segurança jurídica das instituições, em obediência à Constituição Federal em vigor. 
Os membros do FPDVV chamaram a atenção para o fato de que uma das consequências (aparentemente inesperadas) da decisão do Tribunal de Justiça é que, com a invalidação do artigo 137, acabava-se voltando para padróes anteriores, presentes no PL 034 (que dera origem à Lei 4.575/2007). Tais padróes representariam, em relação àquele artigo, um "retrocesso social e ambiental", o que seria um contrassenso, já que o objetivo da decisão do Tribunal de Justiça, e que estaria expresso no voto de um dos juízes registrado no acórdão, era justamente combater o "retrocesso social e ambiental".

A promotora Maria leu então o voto de um dos juízes cuja intenção, em sua interpretação, seria claramente a de evitar o "retrocesso social e ambiental" e apontou que estávamos diante de um dilema: entre o "princípio da legalidade", que indicava que o artigo 137 deveria ser todo revogado, incluindo as informaçóes em seus quadros anexos, e o risco de retrocesso social e ambiental, representado pela volta aos níveis do PL 034. Sugeriu então que se modificasse um aspecto específico do quadro, com a concordância da Prefeitura e do FPDVV, entre eles a definição da altura de um prédio (por exemplo, se a caixa d'água também seria incluída no cálculo). A promotora Maria sugeriu que o Legislativo municipal concordaria também, apesar de que nenhum vereador, dos poucos presentes, tivesse se manifestado nesse sentido.

O representante do Sinduscon foi crítico dessa postura e destacou que tal mudança no texto era ilegal, já que este já teria sido discutido no Comdur, e questionou se, sendo este o caso, poderiam aprovar outras emendas naquela reunião, ao que a promotora Maria respondeu enfaticamente que não. Assim, menos de dez minutos depois de a promotora Carla fazer um discurso enfático pela "legalidade", afirmando que aquele não era o espaço para aprovar mudanças no texto, a promotora Maria sugeriu exatamente o contrário, em nome da proteção do meio ambiente, contra o retrocesso ambiental. Tudo se deu, no entanto, sem que as promotoras parecessem, para o público, estar discordando explicitamente! Em conversas durante a audiência, no entanto, eu percebia que não estava muito claro, mesmo para membros do FPDVV, o que estava sendo decidido naquele momento.

O presidente do Sinduscon não concordou com a ideia de que a reunião terminara em consenso, divergindo, assim, do que propôs matéria no jornal Século Diário, que dizia que o "encontro terminou em consenso". ${ }^{17}$ Segundo ele, aquela foi a pior reuniáo entre aquelas de que participara. Destacou que a mudança no conceito de altura dos prédios não deveria ter sido feita, porque aquele não era um fórum legítimo. Esse quesito já teria sido discutido no Comdur, espaço em que teriam sido feitos os "arranjos" para a produção de um texto de lei provisório que 
pudesse vigorar até a criação de um novo PDM, o que poderia demorar até dois anos. Destacou ainda que, apesar de o Ministério Público ter criticado a forma como o PDM foi construído, sem audiências públicas, acabou fazendo o mesmo ao realizar mudanças no texto da lei no mesmo dia em que este seria votado pela Câmara Municipal.

Destaco ainda que, como apontou o presidente do Sinduscon, o FPDVV não reconhece a legitimidade dos representantes populares do Conselho Comunitário de Vila Velha que fazem parte do Comdur. De forma um tanto irônica, o presidente do Sinduscon, Sr. Aristóteles, disse: "eles precisam decidir quem representa a sociedade".

Aproximávamo-nos, a esta altura, do fim da reunião e, depois de outros presentes tecerem comentários, perguntei à mesa de promotores se o Tribunal de Justiça do ES não deveria participar da discussão em curso, já que sua decisão acabou, mesmo sem que fosse previsto, produzindo "insegurança jurídica" (categoria recorrentemente utilizada pela mesa durante a reunião). A promotora Maria e o promotor Paulo afirmaram veemente, no entanto, que isso não fazia parte da tradição do tribunal e que os juízes provavelmente não participariam, para proteger a imparcialidade do tribunal. De acordo com os promotores, participar do processo de construçáo do consenso seria visto pelos juízes como algo que comprometeria a imparcialidade do tribunal, caso os juízes atuassem como conciliadores entre as partes.

Ocorreu-me, no entanto, a questão: por que a mesma problemática da imparcialidade não se colocava para os promotores a respeito de sua própria atuação no conflito? Afinal de contas, os promotores são parte judicial na Adin contra a Prefeitura e a Câmara Municipal e, simultaneamente, desempenham o papel de "conciliadores" nos desdobramentos extrajudiciais do conflito a respeito do PDM. Assim, em duas instâncias do mesmo conflito, os promotores desempenham papéis diferentes — ora parte judicial, ora conciliadores entre as partes.

Observei que em suas falas os promotores associam esse papel extrajudicial do Ministério Público, que chamam de "preventivo e resolutivo", a uma ampliação do consenso na resoluçáo dos conflitos: "buscando mais do que nunca uma resoluçấo consensual, dialogada com a sociedade civil e todos os atores que envolvem os anseios da coletividade [...]". ${ }^{18}$ Mas é nessas "conciliaçóes" extrajudiciais que a ambiguidade do interesse público representado pelo Ministério Público fica mais explícita. A forma como a promotora Maria conduziu a reunião, abrindo a ocasiáo de maneira enfática, usando um tom professoral e tomando a caneta como continuação de seu dedo indicador para enfatizar sua fala, a forma como conseguiu propor mudanças no texto substitutivo ao PDM e, sobretudo, 
o conteúdo político-ideológico de suas falas, contrastando a "agenda verde" do meio ambiente com a "agenda marrom" da indústria da construção civil, permite aproximá-la da figura de uma empreendedora política e moral, ${ }^{19}$ já que busca não apenas fiscalizar as políticas públicas, mas influenciar seus fins.

Nessas situações, os membros do MP se aproveitam do capital moral que acompanha a figura do promotor em nossa sociedade: ao mesmo tempo que são parte nos processos judiciais, sua atuação extrajudicial como conciliadores é legitimada simbolicamente pela ideia de que são representantes imparciais do interesse público. Em outras palavras, o empreendedorismo moral e político dos promotores usufrui da representação do MP como instituição que estaria acima dos interesses particulares dos grupos envolvidos no conflito. Existe, portanto, uma solidariedade entre a concepção do interesse público como aquilo que se refere a um bem comum indefinido e abrangente e essa ideologia que concebe o MP como uma entidade isenta dos interesses particulares que formam a sociedade.

Por outro lado, contrariando essa ideologia da isenção e imparcialidade dos promotores, em diversas ocasióes o perfil pessoal dos membros do MP era objeto de comentários dos membros do FPDVV e avaliado do ponto de vista de seu interesse em se envolver no caso. Nesse sentido, preferiam entrar em contato com um promotor em detrimento de outro. Uma militante do FPDVV me disse que, comparado a certa promotora, outro promotor era um "freio de máo", porque com ele os processos ficavam "engavetados". Outro militante afirmou que esta promotora era grande aliada dos movimentos sociais. Esse conhecimento sobre o perfil de cada promotor tem sido adquirido no próprio processo de luta social e estas falas mostram que, aos olhos destes interlocutores, a atuação dos promotores não está baseada somente em critérios objetivos e técnicos, mas é influenciada por elementos subjetivos que constituem o "perfil" de cada promotor.

$\mathrm{Na}$ entrevista que fiz com o presidente do Sinduscon, ele destacou como negativo o fato de que o que chamou de "independência funcional" tenha como consequência a influência da "consciência" individual dos promotores em suas açôes. Fez analogia com o papel desempenhado pela consciência dos juízes na sociedade brasileira. Em suas palavras, "cada cabeça é uma cabeça”. Ele destacou que isso produziria imprevisibilidade jurídica e afetaria negativamente os contratos e o planejamento da indústria, acrescentando custos aos empreendimentos.

Fica claro, assim, que as alegaçóes dos promotores de que defendem o interesse público, no sentido do interesse "da sociedade", obscurecem a complexidade de interesses em jogo. A observação de conflitos como o que descrevi aqui mostra também que, de uma perspectiva sociológica, talvez fosse mais apropriado encarar as práticas dos promotores como mais um desses interesses. 
A seguir, vou mostrar como nos Estados Unidos prevalece outra perspectiva de interesse público, concebido explicitamente como o interesse de grupos específicos e não como o interesse "da sociedade". Indicarei, ao final do texto, que essas diferenças indicam concepçóes contrastantes de bem comum: uma orientada por uma perspectiva mais holista, no direito brasileiro, e outra orientada por uma perspectiva mais individualista, no direito dos Estados Unidos.

\section{Public interest nas açóes judiciais coletivas nos Estados Unidos}

Nos itens acima, mostrei como o discurso dos promotores de que representam "a sociedade", em um sentido holístico, obscurece o fato de que há diferentes interesses em jogo no conflito sobre o PDM e de que os interesses dos promotores estáo mais afinados com os de determinados grupos do que de outros. Esta ambiguidade toma forma na dupla participação dos promotores, como parte judicial e como conciliadores extrajudiciais no mesmo conflito. Obviamente, não discuto aqui o mérito político das açôes dos promotores. De fato, acompanhei o conflito junto do FPDVV e, assim como seus membros, sou pessoalmente contrário ao modelo de expansáo imobiliária dominante em Vila Velha.

No entanto, o que quero destacar, para efeito de comparação contrastiva, é que o que observei no Brasil difere do que observei nos Estados Unidos, onde o interesse público levado à justiça por firmas privadas de advocacia representa o interesse de grupos específicos, que não pretendem englobar a totalidade dos interesses da sociedade; são explicitamente parciais. Em outras palavras, a legitimidade formal do interesse levado à justiça não depende de que seja apresentado em um sentido abrangente, como o interesse de "toda a sociedade". $\mathrm{Na}$ verdade, a reivindicação de um interesse público holístico, como é familiar ao cenário brasileiro que descrevi, impediria a aceitação do caso por Cortes nos Estados Unidos, sob a acusação de representarem um interesse público "indiferenciado". Assim, diferenciar o grupo do resto da sociedade em geral é condição formal para que o caso seja ouvido nas Cortes.

Justificadas de diferentes maneiras ou combatidas por seus oponentes, as limitaçóes para iniciar uma ação judicial estão baseadas em um requerimento legal chamado standing to sue. Esse termo constitui uma das problemáticas obrigatórias (Bourdieu, 2011) das açôes judiciais que têm como tema o interesse público nos Estados Unidos. Um dos elementos do standing to sue é a exigência de que um dano concreto a alguma entidade legalmente identificável possa ser demonstrado. Exigências como essa derivam basicamente de interpretaçóes pelas Cortes do terceiro artigo da Constituiçáo dos Estados Unidos, que limita a extensão do poder judicial aos "casos e controvérsias". 
Um advogado de Nova York que entrevistei me falou que via de maneira positiva a necessidade de que grupos tenham sofrido um dano concreto ou iminente para que possam ajuizar uma ação, já que isso evitaria o que chamou de usos políticos das açôes judiciais: "é positivo, as Cortes precisam de controvérsias reais, não são espaços para questôes políticas" ${ }^{20}$. Essa questão do standing to sue foi o primeiro ponto que ele levantou durante a entrevista, espontaneamente. Após entrevistá-lo, encontrei na internet um artigo seu em que ele elabora esse tema (Sandler \& Shoebrod, 2004) .

Outro especialista na área, Jonathan Adler (2001), acrescenta que o aumento do volume de açôes judiciais para a proteção do meio ambiente não implica necessariamente uma melhora na qualidade dos índices ambientais. Segundo ele, muitas ações são utilizadas como ferramentas políticas contra grandes corporações por grupos ambientalistas que atuam em escala nacional e possuem orçamentos milionários. Eles utilizam as açôes para receber custos advocatícios ou acordos judiciais, que lhes permitem financiar outras açôes, fazendo dos processos judiciais instrumentos econômicos para fins políticos.

Outros autores, por outro lado, acreditam que o afrouxamento dos requisitos para ter standing to sue representa uma vitória para a proteção ao meio ambiente. Esse foi o caso da opiniáo dissidente do juiz William O. Douglas, da Suprema Corte dos Estados Unidos, no caso Sierra Club v. Morton (1972). O caso surgiu após o governo da Califórnia liberar uma licença para o grupo Walt Disney desenvolver um parque recreativo em uma área de beleza cênica e natural chamada Mineral King, próxima ao Sequoia Park. O Sierra Club, uma organização não governamental, entrou com uma ação contra a liberação de licenças, e seus argumentos giraram em torno dos possíveis impactos do projeto sobre as características naturais da área.

Mas a opinião majoritária da Suprema Corte considerou que a exigência de dano concreto não foi satisfeita, já que o grupo expressou somente seu interesse na defesa das áreas selvagens, em vez do usufruto dessas áreas pelos membros do grupo. Nesse caso, por meio de uma distinção entre interesses ideológicos (a proteção das áreas selvagens) e interesses materiais (por exemplo, se o Sierra Club tivesse feito referência ao usufruto dessas áreas pelos seus membros), a Corte decidiu que interesses "ideológicos" não forneciam standing to sue, dado que não permitiam identificar um dano concreto, exigência processual de que a parte que exige o direito esteja entre os que sofreram o dano (Stewart, 1975).

Em sua opinião dissidente, o juiz William O. Douglas afirmou que os recursos naturais, em si, deveriam ter acesso à justiça, possivelmente representados por 
aqueles que, mesmo morando a milhares de milhas dessas áreas, possuem interesse em preservá-la:

aqueles que praticam hiking em Appalachian Trail, até Sunfish Pound, New Jersey e acampam ou dormem lá, ou correm por Allagashian Maine, ou escalam os Guadalupes no oeste do Texas, ou que fazem canoagem no Quetico Superior, em Minesota, certamente devem ter standing para proteger aquelas maravilhas naturais diante de Cortes ou agências, ainda que vivam a 3.000 milhas de distância. Aqueles que sáo meramente capturados por notícias ou propaganda ambiental e correm para proteger estas águas ou áreas podem ser tratados de maneira diferente. ${ }^{21}$

Neste caso, apesar de o Sierra Club ter tido seu caso rejeitado, a Corte decidiu também que, se tivessem apontado membros que utilizassem de fato a área, isso bastaria para terem a ação aceita, já que isso constituiria um interesse concreto. Note-se que, na opinião dissidente de Douglas, apesar de propor a inovação de que elementos inanimados da natureza possuam direitos, ele aponta que, nessa hipótese, esses elementos deveriam ser representados por aqueles que utilizam a área e não "aqueles que são meramente capturados por notícias ou propaganda ambiental e correm para proteger estas águas ou áreas".

Percebe-se, portanto, que standing to sue em casos envolvendo interesse público e meio ambiente nos Estados Unidos constitui uma das problemáticas obrigatórias desse campo legal. De maneira geral, as Cortes resistem em reconhecer um interesse público que não esteja relacionado a grupos específicos e que remeta a entidades genéricas como "o povo americano".

Há de se notar a solidariedade ideológica entre essa concepção atomista de interesse público e o papel desempenhado por escritórios privados de advocacia, conhecidos como private public interest law firms. Diferente do Brasil, portanto, onde prevalecem as açôes judiciais iniciadas pelo Ministério Público, nos Estados Unidos, o interesse público é algo a ser promovido por instituiçôes que atuam no mercado dos serviços legais.

Esse tipo de escritório de advocacia se diferenciaria dos demais empreendimentos legais privados porque seu objetivo não seria somente lucrar, mas também dedicar uma parte, maior ou menor, do seu trabalho à promoção do interesse público. A distinção entre as açôes civis que são caracterizadas como empreendimentos econômicos e as que constituem trabalhos para o interesse público surgiu para mim, pela primeira vez, em uma conversa com membros da Environmental Law Clinics na Universidade Stanford. Esse centro treina os alunos da universidade para atuarem em casos desse tipo. Naquela ocasião, eles me explicaram que seu trabalho se diferenciava do trabalho de escritórios voltados 
para casos que envolvem açóes civis tradicionais nas Cortes de common law; por exemplo, quando pessoas se sentem lesadas por um produto que compraram e buscam compensaçôes financeiras.

Casos desse tipo, disseram, dependem de que os advogados identifiquem neles um empreendimento econômico viável. Esses casos costumam também dar uma má reputação à corporação dos advogados quando os clientes ganham cupons insignificantes e a firma fica com uma parte relativamente maior do que os clientes quando tomados individualmente. Resulta disso uma série de piadas já tradicionais na sociedade americana sobre o interesse pecuniário dos advogados. Isso ficou claro quando os membros da Stanford Environmental Law Clinics me disseram, entre risos, que o resultado dos casos que defendem não são cupons, mas mudanças em políticas públicas, por exemplo.

Acompanhei um caso na Califórnia, entre 2010 e 2011, em que algumas cidades localizadas na Baía de San Francisco, como Palo Alto e Atherton, desafiaram judicialmente uma agência estadual porque o projeto do trem de alta velocidade (High Speed Rail Project) que ligaria Los Angeles a San Francisco incluía uma rota que atravessaria suas vizinhanças. A trajetória das duas principais ações judiciais enfrentadas pela agência estadual foi-me apresentada por Stuart Flashman, que trabalha como advogado no processo, representando os queixosos. $\mathrm{O}$ advogado me explicou como a discussão sobre o projeto datava da década de 1990. Em 1996, o Legislativo da Califórnia criou uma comissão para estudar a possibilidade de criação de um trem de alta velocidade que ligasse as regióes de Los Angeles, Central Valley e San Francisco Bay Area. Após dois anos de audiências públicas e estudos, a comissáo chegou à conclusão de que o projeto era viável, e então foi criada a High Speed Rail Authority (HSRA), que é a agência estadual responsável pelo projeto.

Segundo Flashman, a principal questão que surgiu foi sobre dois caminhos possíveis para ligar a Bay Area ao Central Valley, uma vez que existe uma cadeia de montanhas chamada Diablo Range separando as duas áreas. Segundo o advogado, sob pressão de membros da agência estadual que teriam seus interesses ligados à cidade de San Jose, o Pacheco Pass foi escolhido em detrimento do Altamont Pass. Como consequência dessa escolha, o trem passaria por uma série de cidades, como San Jose, Palo Alto, Atherton e Menlo Park, produzindo um impacto que passou a ser problematizado por suas respectivas administraçóes. $\mathrm{O}$ argumento das cidades afirmava basicamente que a agência, apesar de possuir "deferência em caso de dúvidas técnicas", não teria avaliado de maneira apropriada outras opçóes de trajeto, como previsto pelo estatuto ambiental CEQUA (California Environmental Quality Act). 
Por outro lado, as cidades eram acusadas por alguns simpatizantes do projeto de agirem em uma lógica Not in My Back Yard (NIMBY). Essa expressão denota interesses econômicos, ou mesmo estéticos, mesquinhos dos proprietários de imóveis na regiáo, enquanto a agência estatal tentaria mostrar que a construção do trem beneficiaria toda a sociedade californiana. Uma cidadã de Palo Alto chamada E. A. ${ }^{22}$ que realizou os primeiros cálculos que identificavam a ausência de dados substantivos nos relatórios do projeto, respondeu assim às críticas de um website que acusava os plaintiffs (queixosos) de NIMBY:

meu nome é E.A. e você fez referência ao meu trabalho em seu artigo que foi postado hoje em sfist.com sobre o High Speed Rail. Você afirma que tenho "um claro objetivo de manter o trem longe do meu quintal". Eu afirmaria oficialmente que não tenho este tipo de motivação. Parece difícil para as pessoas acreditar, mas o que queremos é nada mais do que ver um processo de política pública de melhor qualidade, em termos de transparência e do uso dos fatos.

[...] Nós temos percebido que a presunção das pessoas de que qualquer crítica só pode ser motivada por interesses próprios é parte do problema. Isso permite aos promotores do projeto desqualificar qualquer crítica como orientada por uma lógica Not in my Back Yard (NIMBY). Isso elimina a prática de checks and balances e todas as coisas que levam a projetos bem planejados. ${ }^{23}$

Vemos, portanto, que açóes desse tipo correm o risco de ser deslegitimadas publicamente por não levarem em consideraçáo interesses mais amplos do que os de suas vizinhanças. Náo se trata aqui de identificar se os grupos agindo contra o projeto estão realmente preocupados com sua transparência ou se estão apenas preocupados, por exemplo, com o impacto da construçáo do trem sobre o valor imobiliário de suas casas. O dado objetivo é que a categoria acusatória NIMBY tem o objetivo de diminuir o valor moral das açóes contra o projeto, acusando-as de expressarem os interesses econômicos mesquinhos daquelas vizinhanças.

Dessa maneira, enquanto de um ponto de vista judicial formal precisam apresentar um interesse público limitado para terem seu caso aceito pelo sistema de justiça, diante da opiniáo pública, os críticos ao projeto são deslegitimados por agirem de acordo com uma noção muito limitada de bem comum.

\section{Consideraçóes finais}

Apesar de que, no caso brasileiro, eu tenha me posicionado politicamente junto ao FPDVV e, portanto, também ao MP, contra o modelo dominante de expansão imobiliária em Vila Velha, isso não me impediu de estranhar metodologicamente o papel dos promotores. Assim, observei que uma estratégia 
recorrente para legitimar seu papel no conflito sobre o PDM de Vila Velha foi reivindicar que representavam os interesses "da sociedade" e afirmar que fora "a sociedade" que buscara a representação do Ministério Público. Mostrei que há uma clara ambiguidade no papel dos promotores, expressa no fato de que o Ministério Público era parte no processo judicial contra a Prefeitura e o Legislativo municipais, ao mesmo tempo que os promotores desempenhavam o papel de conciliadores nos desdobramentos extrajudiciais do mesmo conflito.

Indiquei que essas conciliaçóes extrajudiciais foram apresentadas pelos promotores como espaços de produção de consensos, mas a observação mostrou que essa não foi necessariamente a impressão dos participantes. Por exemplo, uma das partes envolvidas no conflito, representada pelo presidente do Sinduscon, sentiu que não encontrou na reunião um espaço para o acolhimento de suas propostas. Mais do que isso, apontou que os promotores teriam promovido mudanças no texto da lei que iam de encontro ao que havia sido decidido no Conselho Municipal de Desenvolvimento Urbano, fórum que, para o representante da indústria da construção civil, seria formalmente mais legítimo do que as reuniôes na sede MP/ES, conforme é previsto pelo Estatuto das Cidades.

Essa (im)parcialidade dos promotores torna-se paradoxal quando notamos que há também uma preocupação por parte deles em não se "contaminar" com os interesses político-partidários presentes no FPDVV. Talvez isso explique, ao menos em parte, por que os promotores não quiseram assinar, com o FPDVV, uma cartilha destinada à população, que descrevia em linguagem acessível os aspectos inconstitucionais do PDM. Uma interlocutora do FPDVV me sugeriu que essa negativa provavelmente se devia à grande participação de políticos ligados a partidos nas reunióes do FPDVV.

Apesar de quererem se distanciar dos políticos, os promotores usam discursos com uma carga político-ideológica forte. Isso fica claro, por exemplo, quando opõem a "agenda marrom" da indústria da "construção civil" à "agenda verde" do "meio ambiente". Nessas situaçôes, os promotores expóem suas preocupaçóes com os fins últimos das políticas públicas e não só sua adequação aos preceitos legais. Assim, mais que fiscalizar o serviço público, a linguagem dos promotores expressa uma preocupação em interferir nos fins das políticas públicas. Com isso, quero destacar que a definição abrangente de interesse público como o interesse da sociedade tomada como totalidade somado à parcialidade da atuação dos promotores no caso concreto constitui um paradoxo central em processos judiciais e extrajudiciais como esse, em que o que está em jogo é a definição dos parâmetros de políticas públicas, como é o caso do PDM. 
Argumentar-se-ia que a parcialidade dos promotores é constitutiva de toda atividade humana, como sugeriu em certa ocasiāo o próprio presidente do Sinduscon. No entanto, o que explicito aqui são as estruturas sobre as quais está fundada a (im)parcialidade nesse caso: a dupla atuação dos promotores, em um mesmo conflito, como partes judiciais e "conciliadores" extrajudiciais entre as partes. Essa dupla atuaçáo permite que a parcialidade dos promotores encontre nas "conciliaçôes" extrajudiciais um espaço para exercer sua influência sobre os desdobramentos do PDM, sem a supervisão do Judiciário.

Assim, esses papéis ambíguos para um observador externo foram amplamente naturalizados pelos atores do conflito sobre o PDM, independente de suas posiçóes dentro do conflito. $\mathrm{O}$ próprio presidente do Sinduscon parece menos crítico do lugar reservado ao MP em conflitos desse tipo do que da forma como os promotores desempenharam seus papéis nesse caso específico. Ele fez, em entrevista, asserçóes como a de que o MP "faz o que a sociedade gostaria de fazer", o que expressa que também reconhece, pelo menos minimamente, a legitimidade formal da participação dos promotores nos fóruns, judiciais e extrajudiciais, sobre o PDM.

Demonstrei ainda, além das vicissitudes e dos aspectos descritivos dos conflitos apresentados, como, em cada sociedade estudada, as concepçóes de interesse público, ora holistas, ora individualistas, se articulam ideologicamente com determinados atores preferenciais - o Ministério Público, representando o "Estado pacificador", no caso brasileiro, e os escritórios privados de advocacia, representando o mercado de serviços legais, no caso norte-americano. Deve ficar claro, no entanto, que holismo e individualismo não são bons ou ruins em si, mas princípios que podem estar presentes ao mesmo tempo em diferentes sociedades, sendo enfatizados ou silenciados a depender do contexto. Meu débito aqui é, claro, com Louis Dumont $(1994 ; 2000)$ e também com os usos feitos por DaMatta (1982) e Kant de Lima (2008) da preocupação com os efeitos desses princípios no espaço público e na administração de conflitos no Brasil.

Seja observando reuniōes na sede do Ministério Público, seja analisando textos de especialistas do campo do direito, seria difícil que eu tomasse consciência do nosso sistema e fosse capaz de relativizá-lo sem o contraste e a distância que a referência comparativa coloca (DaMatta, 1982). Essa dificuldade se deve em grande medida ao fato de que "os elementos de base da ideologia permanecem quase sempre implícitos” (Dumont, 2000:32).

O material e as reflexóes apresentadas neste artigo, ao explicitarem os significados subjacentes às categorias "interesse público" e public interest, mostram que as descrições de processos de judicialização da política, como fenômenos globais, não devem pressupor homogeneização dos sistemas políticos 
e legais nacionais. Ainda que não possamos falar em tradiçôes jurídicas como ilhas isoladas, os elementos que apresentei indicam que são diferentes os dilemas que cada sociedade enfrenta na administração judicial e extrajudicial de conflitos envolvendo interesse(s) público(s). Minha proposição é que esses dilemas se devem não somente à complexidade de temas como conflitos ambientais, mas à forma como estes se relacionam com tradiçôes políticas e jurídicas longamente estabelecidas.

Recebido em 14/07/2014

Aprovado em 17/02/2016

Márcio Filgueiras é professor de ciências sociais e humanas do Instituto Federal do Espírito Santo, campus Piúma. Formado em ciências sociais pela Universidade Federal do Espírito Santo. Mestre (2008) e doutor (2012) em antropologia pela Universidade Federal Fluminense, quando usufruiu de bolsa Capes/Fulbright para estágio na Universidade Stanford (2010-2011). Recebeu menção honrosa no concurso ABA/Ford de Direitos Humanos em 2008. Seus interesses envolvem antropologia do direito, meio ambiente e grupos tradicionais. E-mail: mpfilgueiras@gmail.com

\section{Notas}

1. Entre 2010 e 2011, usufruí de bolsa da Capes/Fulbright, período em que morei na Califórnia e fui estudante visitante na Universidade de Stanford, como parte do doutorado em antropologia defendido no Programa de Pós-Graduação em Antropologia da Universidade Federal Fluminense (2012).

2. Isso se expressa nos temas de pesquisa que povoaram a imaginação de antropólogos pioneiros no século XIX, como Lewis Morgan e Henry Maine.

3. A ação popular, no entanto, permite que cidadãos ajam diretamente. Mas também aqui, não precisam demonstrar que sofreram danos específicos.

4. Expressão usada recorrentemente nos Estados Unidos que significa algo como "um interesse concreto no caso".

5. Como expresso na opiniấo majoritária em Sierra Club v. Morton (1972).

6. Não há definição de interesse coletivo ou interesse difuso na legislaçấo brasileira. $\mathrm{Na}$ doutrina, por outro lado, podemos encontrar definiçôes mais ou menos consensuais. Enquanto interesses coletivos se referem a grupos identificáveis legalmente, como os 
trabalhadores de uma empresa, os interesses difusos se referem a objetos tidos como indivisíveis (como um rio, por exemplo) e a pessoas indeterminadas, como "o povo brasileiro" ou "as futuras geraçóes". O meio ambiente é entendido pela lei e pela doutrina jurídica brasileira como um interesse desse segundo tipo: ele seria um só, indivisível, e pertenceria à sociedade brasileira tomada em sua totalidade.

7. Documento previsto pelo Estatuto das Cidades. Deve ser construído com base em consulta pública e estabelece os parâmetros urbanísticos municipais.

8. Adin no 1000800068346834, de 27 de março de 2008.

9. Foi a convite do colega sociólogo Sandro Juliati que comecei a frequentar o FPDVV, que se reunia na sede da Associação de Moradores da Praia da Costa, um dos bairros mais caros da cidade, pelo menos duas vezes por mês.

10. Promotora Maria, do MP/ES, em entrevista concedida à Rádio CBN. Disponível em: http://gazetaonline.globo.com/_conteudo/2013/07/cbn_vitoria/ entrevistas/1454286-ministerio-publico-afirma-que-nao-ha-interesse-em-interferir-nosetor-da-construcao-civil.html. Acesso em: 26/07/2013.

11. Adin 100110030515, de 15 de setembro de 2011.

12. Nomes fictícios.

13. Centro de Apoio Operacional de Defesa do Meio Ambiente, Bens e Direitos de Valor Artístico, Estético, Histórico, Turístico, Paisagístico e Urbanístico, sediado no $\mathrm{MP} / \mathrm{ES}$.

14. Esses índices determinam a área que pode ser construída em um terreno.

15. Apesar de a promotora ter utilizado a expressão "acordinhos", esta não foi reproduzida no registro da ata de reunião.

16. Zona de Ocupação Preferencial.

17. Disponível em: www.seculodiario.com/exibir.php?id=9143. Acesso em: $13 / 09 / 2013$.

18. Promotor Paulo, em evento na sede do MP/ES, em Vila Velha, em que os promotores lançaram seu Plano de Ação para 2013.

19. No sentido atribuído por Becker (1991), empreendedores morais são aqueles que promovem valores e visões de mundo de modo a definir socialmente as situaçóes e seus personagens.

20. Ross Sandler, em entrevista: "it's positive, courts need real controversy, it is not the place for political issues". Ross Sandler é diretor e fundador do New York Law School's Center for New York City Law. É membro do corpo docente da New York Law School. É também um membro do New York Procurement Policy Board.

21. Disponível em: http://caselaw.lp.findlaw.com/cgi-bin/getcase. pl?court=us\&vol=405\&invol=727. Acesso: em 16/10/2013.

22. Cofundadora da organização Californians Advocating Responsible Rail Design.

23. Disponível em: http://sfist.com/2011/07/21/palo_alto_menlo_park_would_ prefer_t.php. Acesso em: 09/07/2012. 


\section{Referências}

ADLER, Jonathan H. 2001. "Stand or deliver: citizen suits, standing, and environmental protection”. Duke Environmental Law \& Policy Forum, 12:39-84.

BECKER, Howard. 1991. Outsiders: studies in the sociology of deviance. New York: The Free Press.

BOURDIEU, Pierre. 2011. A economia das trocas simbólicas. São Paulo: Perspectiva.

DAMATTA, Roberto. 1982. Relativizando: uma introdução à antropologia social. Rio de Janeiro: Vozes.

DUMONT, Louis. 1994. German ideology: from France to Germany and back. Chicago e Londres: University of Chicago Press.

2000. Homo Aequalis: gênese e plenitude da ideologia econômica. Florianópolis:

Edusc.

DURKHEIM, Émile. 1973. As formas elementares da vida religiosa. São Paulo: Abril Cultural.

KANT DE LIMA, Roberto. 2008. Ensaios de antropologia e de direito. Rio de Janeiro: Lumen Juris.

LOBINO, Camilla Ferreira. 2008. As entidades associativas não governamentais e o monocultivo do eucalipto no Espirito Santo. Dissertação de Mestrado, Universidade Federal do Rio de Janeiro.

MAUSS, Marcel \& HUBERT, Henri. 2014. Introduction à l'analyse de quelques phénomènes religieux. Disponível em: http://classiques.uqac.ca/classiques/mauss_marcel/ oeuvres_1/oeuvres_1_1/intro_phenomene_rel.pdf. Acesso em: 20/10/14.

SANDLER, Ross \& SHOEBROD, David. 2004. Democracy by decree: what happens when courts run government. New Haven: Yale University Press.

STEWART, Richard. 1975. The reformation of American Administrative Law. Harvard Law Review, 88(8):1684-1686. 


\section{Resumo}

Neste artigo, as questôes que busco responder dizem respeito a um tema amplamente estabelecido na antropologia, o das diferenças entre sociedades organizadas segundo princípios holistas, em que o valor está no todo social, e aquelas baseadas no indivíduo como um valor moral. Vou mostrar como essa problemática constitutiva do campo antropológico pode lançar luz sobre a compreensão dos significados subjacentes às concepçôes predominantes de interesse público no Brasil e nos Estados Unidos e como estas se expressam na estrutura processual das açôes judiciais coletivas nos dois países.

Palavras-chave: holismo, individualismo, interesse público.
In this paper, I deal with the differences between societies organized through a holistic logic, in which the social value is in the whole, and those based on the individual as a moral value. I will show that this conditioning background of the anthropological field can shed light over the underlying meanings of public interest as a legal construct in Brazil and in the USA and over the procedural structure of public interest litigation in both countries.

Key-words: holism, individualism, public interest. 